\title{
O SUS como Escola
}

\section{The Unified National Health System as a School}

Patrícia Tempsk ${ }^{\mathrm{I}}$

Mayla Borba ${ }^{I I}$

O ensino de Medicina no século 20 pode ser dividido em duas fases. A primeira se estabelece a partir do Relatório Flexner, publicado nos Estados Unidos em 1910 e que tentou nortear o ensino médio americano por uma sólida formação em ciências básicas, com a aprendizagem utilizando o hospital como cenário, além de pouca ênfase na prevenção e promoção de saúde. Num momento histórico marcado por grande diversidade na formação médica, esse documento teve importante papel organizador do ensino e propiciou grande avanço do conhecimento, de tal forma que foi reproduzido em vários países, inclusive no Brasil.

A segunda fase da educação médica se inicia a partir da década de 1970, quando as ideias de prevenção e promoção da saúde e o modelo de multicausalidade das doenças ganham visibilidade a partir do Relatório Lalonde, no Canadá, em 1974. A etiologia das doenças é concebida a partir de fatores ambientais, acesso aos serviços de saúde, estilos de vida e biologia humana. O ser humano e sua doença passam a ser entendidos segundo uma visão de integralidade, tanto do seu sistema orgânico, como da sua inter-relação com o ambiente, seu trabalho e seus semelhantes. A Conferência Internacional da Organização Mundial da Saúde, em Alma-Ata, em 1978, reforça este modelo ideológico da Medicina Integral, a importância da formação de um médico generalista e da Atenção Primária à Saúde, apontando como meta Saúde Para Todos no ano 2000.

Na década de 1980, exatamente dez anos após a Conferência de Alma-Ata, na reunião da Federação Mundial de Educação Médica, constrói-se a Declaração de Edimburgo. Entre outros importantes temas da formação médica, nela se discutem as prioridades e estratégias educacionais, a articulação entre escolas e serviços de saúde e o compromisso social da escola médica.

Tais mudanças no cenário internacional foram acompanhadas no Brasil pelo movimento sanitarista, que culminou com a formação do Sistema Único de Saúde (SUS). Criado em 1988, o SUS tem por princípios ideológicos a universidade, a integralidade e a equidade, além dos princípios organizacionais de descentralização, regionalização e hierarquização. A universalidade entende a saúde como direito dos cidadãos, tendo o Estado a obrigação de promover atenção à saúde. A integralidade concebe a atenção à saúde para além dos meios curativos, envolvendo também os preventivos, nos âmbitos individual e coletivo. Já a equidade garante que todos tenham iguais oportunidades de utilizar o sistema público de saúde. A Constituição Federal afirma que, entre outras responsabilidades, compete ao SUS ordenar a formação de recursos humanos na área de saúde e incrementar em sua área de atuação o desenvolvimento científico e tecnológico.

O desafio apresentado aos educadores médicos no final do século 20 era formar um profissional para esta nova realidade, de integralidade da atenção, com ações de promoção e prevenção da saúde, com compromisso social e que atenda as demandas de saúde da comunidade, sendo parte integrante do SUS. Mas como formar este profissional no modelo hegemônico, biologicista, cartesiano, com pouca ênfase na prevenção e promoção da saúde e focado na doença e não no ser humano doente e na sua realidade?

A década de 1990 foi o momento de reflexão e avaliação do ensino médico no Brasil. Em 1991, institui-se a Comissão Interinstitucional Nacional de Avaliação do Ensino Médico (Cinaem), com representantes da Academia Nacional de Medicina, Associação Brasileira de Educação Médica, Sindicato Nacional dos Docentes das Instituições de Ensino Superior, Associação Nacional de Médicos Resi-

I Faculdade Evangélica do Paraná, Curitiba, Paraná, Brasil; Preseidente do $47^{\circ}$ Congresso Brasileiro de Educação Médica.

II Faculdade Evangélica do Paraná, Curitiba, Paraná, Brasil. 
dentes, Conselho Federal de Medicina, Conselho dos Reitores das Universidades Brasileiras, Conselhos Regionais de Medicina e Federação Nacional dos Médicos. A Cinaem teve como objetivo avaliar os recursos humanos, bem como o modelo pedagógico e sua relação com a qualidade da formação médica, o que evidenciou uma imagem objetiva da escola real e daquela ideal para a realidade brasileira. Esta reflexão foi um terreno fértil para a construção das Diretrizes Curriculares Nacionais para o Curso de Graduação em Medicina, homologadas pelo Ministério da Educação em 2001 e que passam a nortear os cursos de Medicina.

O ensino médico no Brasil inicia o século 21 com o desafio de transformar os currículos, as escolas e os docentes, e avaliar o impacto destas mudanças na formação de um profissional adequado à realidade brasileira: ético, crítico, reflexivo, humanista, capacitado a atuar junto às comunidades, atendendo os principais problemas de saúde da população nos diferentes níveis de complexidade, com visão integralizada da assistência e consciente de seu papel social e cidadania. A escola médica deve ainda incorporar as novas tecnologias educacionais e de assistência e preparar o estudante para buscar com autonomia novos conhe- cimentos, num processo contínuo de atualização. Tais mudanças na educação e na saúde respondem aos desafios construídos ao longo dos últimos 50 anos.

As Diretrizes Curriculares Nacionais passam a ser o norteador na construção e aprimoramento dos currículos das escolas médicas e enfatizam a necessidade de um ensino voltado para a realidade e as necessidades de saúde da população, o que definitivamente será alcançado se o SUS for o cenário de aprendizado, desde a atenção primária até os atendimentos de alta complexidade da atenção terciária. De tal forma que a academia volte os olhos para além dos seus muros e passe a construir parcerias e uma nova forma de entender a formação médica. OSUS tem que ser escola e se fazer escola, assumindo sua responsabilidade na formação de recursos humanos e na construção de conhecimentos. Porém, para o SUS ser escola, é necessário que a gestão do ensino superior mude, que docentes e discentes entendam a importância disto para a saúde da população brasileira e que os gestores municipais e estaduais acolham a academia em seus espaços, como corresponsáveis pela formação dos médicos que futuramente serão força de trabalho no mesmo espaço em que se formaram. 